\title{
Introduction to the Special Issue of Geotechnical and Geological Engineering Entitled: "Thermo-Hydro- Mechanical Behavior of Soils and Energy Geostructures"
}

\author{
John S. McCartney • C. Guney Olgun
}

Published online: 7 March 2015

(C) Springer International Publishing Switzerland 2015

This special issue of Geotechnical and Geological Engineering highlights state-of-the-art research on the thermo-hydro-mechanical behavior of soils, rocks and energy geostructures. Although the impetus of the special issue was to collect journal papers on subjects related to an NSF-funded international workshop on "Thermally Active Geotechnical Systems for Near Surface Geothermal Energy" held in March 2013 at École Polytechnique Fédérale de Lausanne in Switzerland, the special issue expanded to collect a broader set of papers from the field of Energy Geotechnics that involve thermal soil behavior.

A total of 15 journal papers were selected to be published as part of the special issue, and went through the standard peer review process for the journal. Two papers focused on the thermal properties of unsaturated soils. Likos (2014) presented a pore-scale model for predicting the thermal conductivity of unsaturated sands using basic soil properties. Dong et al. (2014)

J. S. McCartney ( $\square)$

Department of Structural Engineering, University of California San Diego, 9500 Gilman Dr, La Jolla,

CA 92093-0085, USA

e-mail: mccartney@ucsd.edu

C. G. Olgun

The Charles E. Via, Jr. Department of Civil and Environmental Engineering, Virginia Polytechnic Institute and State University, 111A Patton Hall, Blacksburg, VA, USA

e-mail: olgun@vt.edu presented an evaluation of various approaches to predict the thermal conductivity of unsaturated soils, and compared them with experimental data for sand, silt and clay. One paper was presented on the thermal volume change of unsaturated soils, and the impact of these volume changes on the response of a heated shallow foundation (Houston et al. 2014). Three papers were published on different aspects of geothermal heat exchangers in conventional applications (boreholes and horizontal trenches). Wu et al. (2014) studied relationships between the thermal conductivity dryout curve for unsaturated soils and the performance of geothermal heat exchangers in horizontal trenches, Ozudogru et al. (2014a) compared the performance of different numerical simulations to evaluate the response of geothermal heat exchangers in vertical boreholes, and Walker et al. (2014) studied the impact of different stratigraphic units on the overall thermal response of a geothermal heat exchanger in a vertical borehole. Seven papers were focused on the thermal and thermo-mechanical response of energy piles. Loveridge et al. (2014) analyzed the response of different types of auger cast piles that were converted into energy piles. Yu et al. (2015) used numerical modeling to evaluate the thermal conductivity of different soil layers from the analysis of a thermal response test on an energy pile. Kramer et al. (2014) evaluated the thermal response of an energy pile in sand constructed within a laboratory container. Murphy and McCartney (2014) studied the 
thermal and thermo-mechanical response of two energy piles during operation of a heat pump used for heating and cooling an 8-story building. Ozudogru et al. (2014b) used a load transfer model to evaluate the role of side shear stresses in the axial stress distribution in energy piles. Chakraborty and Saggu (2014) used the results from a field study on energy piles to calibrate a thermo-elastic finite element analysis, and extrapolated the findings to study the cyclic response of energy piles. Wang et al. (2014) used a thermo-hydro-mechanical elasto-plastic finite element model to study the behavior of a centrifugescale model energy pile installed in an unsaturated silt layer. Two papers were focused on emerging problems in energy geotechnics associated with rocks. Zhu and Arson (2014) developed a coupled model for damage and healing of salt, which is often used in compressed air energy storage (CAES) systems. Mortezaei and Vahedifard (2015) studied the problem of induced seismicity associated with carbon sequestration in subsurface strata.

This suite of papers presents new numerical techniques, experimental data sets from field and laboratory settings, novel investigations into the thermal and thermo-mechanical properties of soils and rocks. Many of the papers have hinted at additional challenges that need to be addressed through further research. These challenges include the roles of cyclic heating and cooling, which was revealed in the work of Chakraborty and Saggu (2014) and Murphy and McCartney (2014). As testing of full-scale energy piles can be expensive, the roles of physical modeling and numerical modeling of these systems needs to be expanded in future years to understand basic mechanisms of energy piles (Kramer et al. 2014; Ozudogru et al. 2014b; Chakraborty and Saggu 2014; Wang et al. 2014; Yu et al. 2015). These challenges also include the role of unsaturated conditions, which can have significant impacts on the heat exchange behavior of heat exchangers (Dong et al. 2014; Likos 2014; Wu et al. 2014) as well as the thermo-mechanical behavior of energy piles and other thermo-active foundations (Houston et al. 2014; Wang et al. 2014). The thermohydro-mechanical behavior of rocks under representative in-situ conditions is an important issue that can shape new energy storage applications (Mortezaei and Vahedifard 2015; Zhu and Arson 2014). Although comparatively mature, the behavior of geothermal heat exchangers can still be better understood to develop easier to use design methods and to consider the role of more complex stratigraphic conditions (Ozudogru et al. 2014a, b; Murphy and McCartney 2014; Yu et al. 2015; Walker et al. 2014). Similarly, as different types of energy pile configurations are developed, thermal analyses that can be readily integrated into whole-building thermal design tools also need to be developed at the same time (Loveridge et al. 2014).

\section{References}

Chakraborty T, Saggu R (2014) Cyclic thermo-mechanical analysis of energy piles in sand. Geotech Geol Eng. doi:10. 1007/s10706-014-9798-8

Dong Y, McCartney JS, Lu N (2014) Review of thermal conductivity models for unsaturated soils. Geotech Geol Eng. doi:10.1007/s10706-015-9843-2

Houston SL, Dye HB, Lingnau B, Houston WN (2014) Thermally-induced settlements for heat generating structures on unsaturated soils. Geotech Geol Eng. doi:10.1007/s10706014-9812-1

Kramer CA, Ghasemi-Fare O, Basu P (2014) Laboratory thermal performance tests on model heat exchanger pile in sand. Geotech Geol Eng. doi:10.1007/s10706-014-9786-Z

Likos WJ (2014) Pore-scale model for thermal conductivity of unsaturated sand. Geotech Geol Eng. doi:10.1007/s10706014-9744-9

Loveridge F, Olgun CG, Brettmann T, Powrie W (2014) Thermal behaviour of three different auger pressure grouted piles used as heat exchangers. Geotech Geol Eng. doi:10. 1007/s10706-014-9757-4

Mortezaei K, Vahedifard F (2015) Numerical simulation of induced seismicity in carbon capture and storage projects. Geotech Geol Eng. doi:10.1007/s10706-015-9859-7

Murphy K, McCartney JS (2014) Seasonal response of energy foundations during building operation. Geotech Geol Eng. doi:10.1007/s10706-014-9802-3

Ozudogru TY, Ghasemi-Fare O, Olgun CG, Basu P (2014a) Numerical modeling of vertical geothermal heat exchanger using finite difference and finite element techniques. Geotech Geol Eng. doi:10.1007/s10706-014-9822-z

Ozudogru TY, Olgun CG, Arson CF (2014b) Analysis of friction induced thermo-mechanical stresses on a heat exchanger pile in isothermal soil. Geotech Geol Eng. doi:10. 1007/s10706-014-9821-0

Walker MD, Meyer LL, Tinjum JM, Hart DJ (2014) Property measurements of stratigraphic units with modeled implications for expected performance of vertical ground source heat pumps. Geotech Geol Eng. doi:10.1007/s10706-0159847-y

Wang W, Regueiro RA, McCartney JS (2014) Coupled axisymmetric thermo-poro-mechanical finite element analysis of energy foundation centrifuge experiments in partially saturated silt. Geotech Geol Eng. doi:10.1007/s10706-014$9801-4 \mathrm{c}$ 
Wu R, Tinjum JM, Likos WJ (2014) Coupled thermal conductivity dryout curve and soil-water characteristic curve in modeling of shallow horizontal geothermal ground loops. Geotech Geol Eng. doi:10.1007/s10706-014-9811-2

Yu KL, Singh RM, Bouazza A, Bui HH (2015) Determining soil thermal conductivity through numerical simulation of a heating test on a heat exchanger pile. Geotech Geol Eng. doi:10.1007/s10706-015-9870-z
Zhu C, Arson C (2014) A model of damage and healing coupling halite thermo-mechanical behavior to microstructure evolution. Geotech Geol Eng. doi:10.1007/s10706-0149797-9 